\title{
Enriching Speaking Fluency through Conversational Gambits and Routines among Iranian Intermediate EFL Learners
}

\author{
Javad Akbari \\ Islamic Azad University, Isfahan (Khorasgan) Branch \\ E-mail: javadakbari92@yahoo.com \\ Received: September 25, $2017 \quad$ Accepted: January 1, $2018 \quad$ Online Published: March 20, 2018
}

\begin{abstract}
The activity of speaking is conducted spontaneously and there is not much time devoted to preplanning and arranging the utterances the speaker intends to deliver. Briefly defined, gambits and routines refer to the words and phrases that facilitate the flow of conversations. As such, one way to help learners acquire oral proficiency is to teach gambits that support the social skills emphasized. The present study aimed to investigate the speaking fluency of Iranian intermediate EFL learners through conversational gambits and routines. To this end, the subjects of the present study consisted of an experimental group and a control group each containing 30 students who attended listening and speaking classes. To count the frequency of gambit tokens and identify their functions, the recorded data were analyzed utilizing Keller and Warner's classification of conversational gambits. The results of the t-test revealed that the experimental group possessed better speaking fluency based on the occurrences of gambit categories. There was a positive correlation between the number of gambits and the scores of fluency test. Evidently, the findings of the present study may have implications for EFL teachers and syllabus designers.
\end{abstract}

Keywords: conversational gambits, gambit categories, gambit tokens, speaking fluency

\section{Introduction}

Language is a fundamental property of human being and can be viewed as a vehicle for communicating meaning and messages. Language is the most important form of human communication. Not only is language an invaluable human property, but it is also the key to all human activities and situations. It is a vehicle through which the world can be understood and appreciated all the time. Without language, people are desperately isolated and helpless from the rest of the world (Norton, 1980).

Wray (2000) stated that conversation has been of primary interest to language researchers. Since everyday conversation is the most occurring language use, among approaches in speaking, Conversation Analysis (CA) has received special attention. CA has been developed for a particular paradigm in the study of naturally-occurring language use. CA maintains that it is possible to analyze talk-in-interaction by examining its recordings alone. Therefore, in CA the focus is on the analysis of talk produced in interactions, and how participants systematically organize their interactions to solve the problems of understanding.

Researchers focused so much on grammar and correctness of the sentences; however, they forgot to teach important skills like getting a conversation started, keeping it going, and ending it. Likewise, how to improve the flow of communication was somehow neglected in the preceding research studies. Moreover, not many attempts have been made to stress the importance of gambits to be utilized in interactional circumstances. Furthermore, the instructional efficacy of gambits and routines in teaching speaking to learners with different proficiency levels has not been under consideration. Researchers did not shed much light upon the considerable influence of using conversational gambits on oral proficiency and speaking fluency of various learners (Yorio, 1980).

In fact, one of the major reasons students do not dare to speak in discussion groups is that they fail to make use of conversational fillers and gambits. By the use of them, they will be able to express their thoughts and come up with new ideas when communicating with other participants in the discussion. As these gambits and routines are utilized, 
rarely do learners happen to have long pauses and hesitations in their speaking. As a result, they succeed in boosting their confidence not only in opening the conversations but also in maintaining and terminating the interactions and discussions (Yorio, 1992).

The more conversational fillers and routines learners utilize in their speaking, the fewer pauses and hesitations they might have while conveying their messages and negotiating meaning. To this end, the present research study attempted to investigate speaking fluency enrichment through conversational gambits and routines among Iranian intermediate EFL learners. In this regard, the significant role of using routine formulae and gambits in teaching speaking to EFL learners was taken into account. Furthermore, another objective of this research is to determine to what extent the use of conversational gambits and routine formulas can help learners boost their level of confidence in speaking.

\section{Literature Review}

It is obvious that conversation involves people taking turn while speaking. Based on turn-taking rules-any listener might be selected to speak next-participants may be addressed to contribute in the discussion. In such a case, the speaker needs time to formulate his/her thoughts and react to what the previous speaker has said at the same time (Keller, 1981).

For this reason, people usually employ a set of gambits to react to the previous utterance, and also they utilize gambits to shift the floor and change the topic in a discussion. Hence, gambits can influence the process of turn-taking in the conversation. In sum, gambits are devices that act as (a) discourse organizers to introduce what the speaker is about to say, (b) strategies to maintain the smooth flow of conversation, and finally (c) pause fillers that buy time while the speaker searches for a word or attempts to hold a turn (Keller, 1981).

From a purely linguistic point of view, it is also possible to identify a further factor for facilitating conversational discourse. The presence or absence of a certain set of signals in the conversationalist's speech will introduce level shifts within the conversation and prepare the listener for the next turn in the logical argument. This set of signals will here be called 'conversational gambits' or 'routine formulas.' They are one of the current discussions in discourse analysis and conversational discourse analysis (Keller, 1981).

A large and growing body of literature has investigated the fundamental importance of conversational gambits and routine formulae in interaction. One of the most popular functions of gambits is that they serve as discourse lubricants or gambits that are "used to lubricate discourse already initiated." Due to this function, they will lead to fewer breakdowns in communication. But it seems that these discourse lubricants can also act as didactic devices.

A considerable amount of literature has been published on how gambits help the conversations to go more smoothly. Accordingly, gambits are recognized as formulaic expressions and play an important role in maintaining the smooth flow of conversation and act as an opening remark (Keller \& Warner, 1994). During a conversation, gambits can help people to indicate the ways of how to start, continue, and also terminate the conversation.

In a study conducted by Sorhus (1997), she observed that twenty percent of all words used in daily conversational interaction and communication were fixed-expressions. Sorhus found out that routine formulas facilitate conversational planning and also maintain a smooth flow of interaction. In this regard, she examined the flow of interactional students and demonstrated that they incorporated a large number of routine formulas and gambits into their conversations and interactions. Finally, she investigated the differential impact of formal and non-formal expressions on the interlocutor.

In recent years, there has been an increasing amount of literature on the use of gambits as an effective tool in managing communication. The key to success while interacting is attributed to the incorporation of gambits. In conversational discourse, gambits can be used not only in the beginning of a conversation, but also in the middle and end of a conversation. Keller (1979) believes that strategies which have an overt and verbal representation in the form of semifixed expressions and are used by speakers to structure their content and their conversational procedure from a psycholinguistic point of view are called gambits.

Coulmas (1981) characterized routine formulae as highly conventionalized pre-patterned expressions whose occurrence is tied to more or less standardized communication situations. He also noted that using routine formulas is important in the handling of day-to-day interactions and dealing with conversational breakdowns. In his research study, he came to a conclusion that using routine formulas and gambits makes the conversation more natural and 


\section{International Journal of Research in English Education}

provides the speech with a proficient flavor. Therefore, speakers feel more confident and relaxed when conveying messages and negotiating meanings.

Faerch and Kasper (1983) considered pause fillers temporal variables rather than strategic devices. Now, the thing is that surely a function of gambits is to give the speaker time in order to organize his thoughts, to understand true value of utterances, and to anticipate the subsequent sentences. One of the most pervasive functions that gambits may have is that they can introduce the general frame within which meaning can be conveyed. So most commonly and most overtly gambits refer to semantic information.

Results from several studies have revealed that an increasing use of routines and gambits can apparently lead to better interaction and communication. Yorio (1992) suggested that employing routine formulas makes the language learner appears native like. Furthermore, the learner will be able to produce more natural utterances and speak with better fluency. Having achieved a great deal of capacity in speaking fluency, the speaker might have the ability to discuss the most challenging issues with complete confidence.

By using formulas, the speaker can be confident that the speech would be understood by the interlocutors in the intended way. Weinert (1995) focused on fluency in production in general, and in speaking in particular. Moreover, faster processing is another function of formulas investigated. Briefly defined, processing will be done more rapidly when speakers make use of formulas and gambits.

A great deal of communicative activity consists of routine formulas that are usually fixed-expressions. Wray (2000) defined a routine formula as: A sequence, continuous, or discontinuous of words or other meaning elements; which is, or appears to be, prefabricated; that is, stored and retrieved whole from memory at the time of use, rather than being subject to generation or analysis by the language grammar. In general, routine formulas are chunks that are specifically bound. They are highly frequent and beneficial for the development of L2 learners' performance (Roever, 2011).

Fluency in production can be conceptualized in four different ways (Kormos \& Denes, 2004). First, Fillmore defined fluency as the ability to talk at length with few pauses and to be able to fill the time with talk. Second, a fluent speaker can not only talk without hesitations but also express his/her message in a coherent, reasoned, and semantically dense manner. Third, a fluent speaker knows what to say in a wide range of contexts. Finally, fluent speakers are creative and imaginative in their language use. Fillmore contended that a maximally fluent speaker has all of the aforementioned abilities.

In fact, the research questions of the present study can be formulated as follows:

1. Does utilization of conversational gambits and routines improve the speaking fluency of Iranian intermediate EFL learners?

2. Is there a correlation between the number of gambits and the scores of fluency test?

\section{Methodology}

\subsection{Design}

All data collected in this research study were numerical and objective. It is a quantitative research study that started with a quasi-experimental design in which a specific hypothesis precedes the quantification of data with follow-up numerical analyses. The investigation compared student test results before and after an instructional treatment in the pretest and posttest respectively. This quantitative research study was confirmatory and outcome-oriented in nature.

\subsection{Participants}

From the population of 150 students, 60 subjects with an intermediate proficiency level studying English at the Islamic Azad University, Khorasgan Branch, Iran were designated for this research study. They were assigned to two groups and each group consisted of 30 students aged between 20 and 30 years. Participants were of both male and female genders. The subjects were selected on the basis of a degree of homogeneity of their English capacity and the number of terms attended in the university. All the participants' native language was Persian and they were generally studying English as a foreign language. 


\section{International Journal of Research in English Education}

\subsection{Instrument}

In order to select the sample classes appropriately, subjects were asked to take the Solution Placement Test (Edward, 2007). In a nutshell, this test includes 50 multiple-choice items which assesses students' knowledge of general English. Grammar, vocabulary, and reading comprehension are examined in this test. The whole administration took, approximately, forty minutes and from the entire population, 60 students with an intermediate proficiency level were chosen.

Prior to the experimentation, a pretest was administered to find out students' knowledge of speaking. A series of thirty speaking fluency tests was given to the students for this purpose. By the administration of this test, the speaking ability of both groups was determined. They were not significantly different regarding their speaking capacity based on the results of the pretest. The participants in both groups were homogeneous.

At the end of the term, a post-test comprised of thirty speaking fluency tests was given to both classes to determine their progress. In one of the classes, speaking was taught in a communicative way along with using conversational gambits and routine formulas whereas the control group was not exposed to any conversational expressions throughout the experimentation. Having considered the methods approached in both classes, the post-test was delivered at the end of the semester. Furthermore, the reliability of both pre-test and post-test was 0.84 calculated by KR-21 formula. In order for the researcher to find out the content validity of the tests, a wide variety of different experienced and knowledgeable teachers were consulted.

\subsection{Procedure}

Students attended the number of 16 sessions, once a week. Learners in the experimental group were engrossed in a situation in which a big number of conversational gambits and routines were employed by the instructor in the process of teaching. Students were always encouraged to spend more time at home practicing these expressions and using them in class as well. The instructor was stressing the importance of learning gambits and utilizing them in appropriate places as well. However, students in the control group were not exposed to any conversational fillers and gambits at all. Even though the students were willing to contribute to the discussions under consideration, they were not much confident and capable to demonstrate their thoughts. From time to time, they were demotivated to take part in class and group activities for their lack of confidence.

The number of routines words employed in the first group was much more in comparison with the second group's conversational gambits. The conversational expressions and routine formulas were recorded and stored for later analysis. Moreover, the number of expressions that were employed in each session was counted and written to be interpreted subsequently. These gambits used in conversations and interactions were entirely clear and obvious; therefore, students used them in order to make up for communication breakdowns and hesitations in their speaking. The conversational gambits and routines bridged the gaps and pauses among utterances and helped the speakers to hold the dyadic interactions and conversations more confidently.

\subsection{Date Analysis}

All the data and results gained through pre-test and post-test were fed into the computer and then analyzed employing SPSS. Data management and analysis were performed using SPSS 24.0 (2010). Technically, quantitative data were analyzed with the help of SPSS program. Participants received 1 point for each correct answer in multiple-choice items in the pre-test and post-test. Descriptive statistics (frequency, mean, and standard deviation) and t-test were used for the analysis of the quantitative data. Descriptive statistics were applied to analyze all quantitative data. In order to count the frequency of gambit tokens and identify their functions, the recorded data were analyzed utilizing Keller and Warner's (2002) classification of conversational gambits.

\section{Results}

\subsection{Homogeneity of Learners in Speaking Fluency}

In order to establish the homogeneity of groups in terms of speaking knowledge prior to the study, a test comprising 30 speaking fluency items was administered to all groups as the pre-test. Then, the performances of the participants on this test were compared and analyzed. The significance value .842 is greater than 0.05 (Table. 2). Thus, it is concluded that all learners were homogenous in their speaking knowledge at the beginning of the treatment. 


\section{International Journal of Research in English Education}

Table 1. Descriptive statistics for the pre-test

\begin{tabular}{llllll}
\hline & Group & $\mathrm{N}$ & Mean & Std. Deviation & Std. Error Mean \\
\hline \multirow{2}{*}{ Pretest } & Experimental group & 30 & 2.9000 & .71197 & .12999 \\
& Control group & 30 & 2.9667 & .71840 & .13116 \\
\hline
\end{tabular}

Table 2. The results of the Independent-Sample t-test for the pre-test

\begin{tabular}{|c|c|c|c|c|c|c|c|c|c|c|}
\hline & & \multicolumn{9}{|c|}{$\begin{array}{l}\text { Levene's Test } \\
\text { for Equality oft-test for Equality of Means } \\
\text { Variances }\end{array}$} \\
\hline & & \multirow[t]{2}{*}{$\mathrm{F}$} & \multirow[t]{2}{*}{ Sig. } & \multirow[t]{2}{*}{$\mathrm{t}$} & \multirow[t]{2}{*}{ df } & \multirow[t]{2}{*}{$\begin{array}{l}\text { Sig. } \\
\text { (2-tailed) }\end{array}$} & \multirow[t]{2}{*}{$\begin{array}{l}\text { Mean } \\
\text { Difference }\end{array}$} & \multirow{2}{*}{$\begin{array}{l}\text { Std. Error } \\
\text { Difference }\end{array}$} & \multicolumn{2}{|c|}{$\begin{array}{l}95 \% \text { Confidence } \\
\text { Interval of the } \\
\text { Difference }\end{array}$} \\
\hline & & & & & & & & & Lower & Upper \\
\hline \multirow{2}{*}{$\begin{array}{l}\text { Pre- } \\
\text { test }\end{array}$} & $\begin{array}{l}\text { Equal variances } \\
\text { assumed }\end{array}$ & s. .040 & .842 & -.361 & 58 & .719 & -.06667 & .18466 & -.43631 & .30297 \\
\hline & $\begin{array}{l}\text { Equal variances } \\
\text { not assumed }\end{array}$ & & & -.361 & 57.995 & .719 & -.06667 & .18466 & -.43631 & .30297 \\
\hline
\end{tabular}

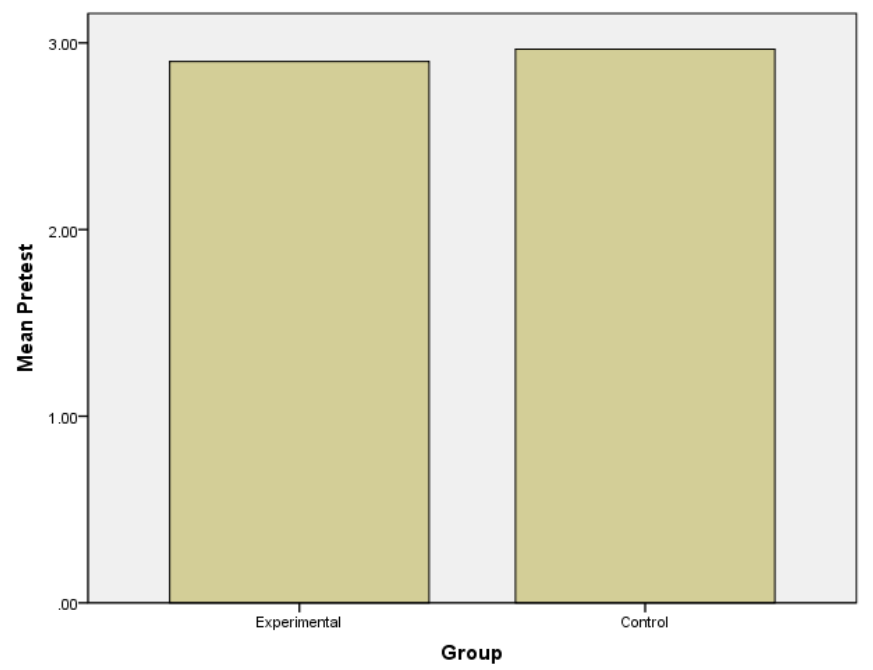

Figure1. Mean scores for pre-test

\subsection{Comparing Experimental and Control Groups after the Treatment}

With regard to means of participants in post-test, all students in the experimental group outperformed the students in the control group. Table 4 illustrates that the significance level calculated for the independent sample t-test is .000, which means that treatment was effective and statistically significant $(\mathrm{p}<0.05)$. 


\section{International Journal of Research in English Education}

Table 3. Descriptive statistics for the post-test

\begin{tabular}{llllll}
\hline & Group & $\mathrm{N}$ & Mean & Std. Deviation & Std. Error Mean \\
\hline \multirow{2}{*}{ Post-test } & Experimental group & 30 & 4.0667 & .82768 & .15111 \\
& Control group & 30 & 3.2000 & .84690 & .15462 \\
\hline
\end{tabular}

Table 4. The Results of the Independent-Sample t-test for the post-test

\begin{tabular}{|c|c|c|c|c|c|c|c|c|c|c|}
\hline & & & \multicolumn{8}{|c|}{$\begin{array}{l}\text { Levene's Test for } \\
\text { Equality of Variances }\end{array}$} \\
\hline & & $\mathrm{F}$ & \multirow[t]{2}{*}{ Sig. } & \multirow[t]{2}{*}{$\mathrm{t}$} & \multirow[t]{2}{*}{ df } & \multirow[t]{2}{*}{$\begin{array}{l}\text { Sig. } \\
\text { (2-tailed) }\end{array}$} & \multirow[t]{2}{*}{$\begin{array}{l}\text { Mean } \\
\text { Difference }\end{array}$} & \multirow{2}{*}{$\begin{array}{l}\text { Std. Error } \\
\text { Difference }\end{array}$} & \multicolumn{2}{|c|}{$\begin{array}{l}95 \% \text { Confidence } \\
\text { Interval of the } \\
\text { Difference }\end{array}$} \\
\hline & & & & & & & & & Lower & Upper \\
\hline \multirow{2}{*}{$\begin{array}{l}\text { Post- } \\
\text { test }\end{array}$} & $\begin{array}{l}\text { Equal } \\
\text { assumed }\end{array}$ & variances .109 & .742 & 4.009 & 58 & .000 & .86667 & .21620 & .43389 & 1.29944 \\
\hline & $\begin{array}{l}\text { Equal var } \\
\text { assumed }\end{array}$ & iances not & & 4.009 & 57.969 & .000 & .86667 & .21620 & .43389 & 1.29945 \\
\hline
\end{tabular}

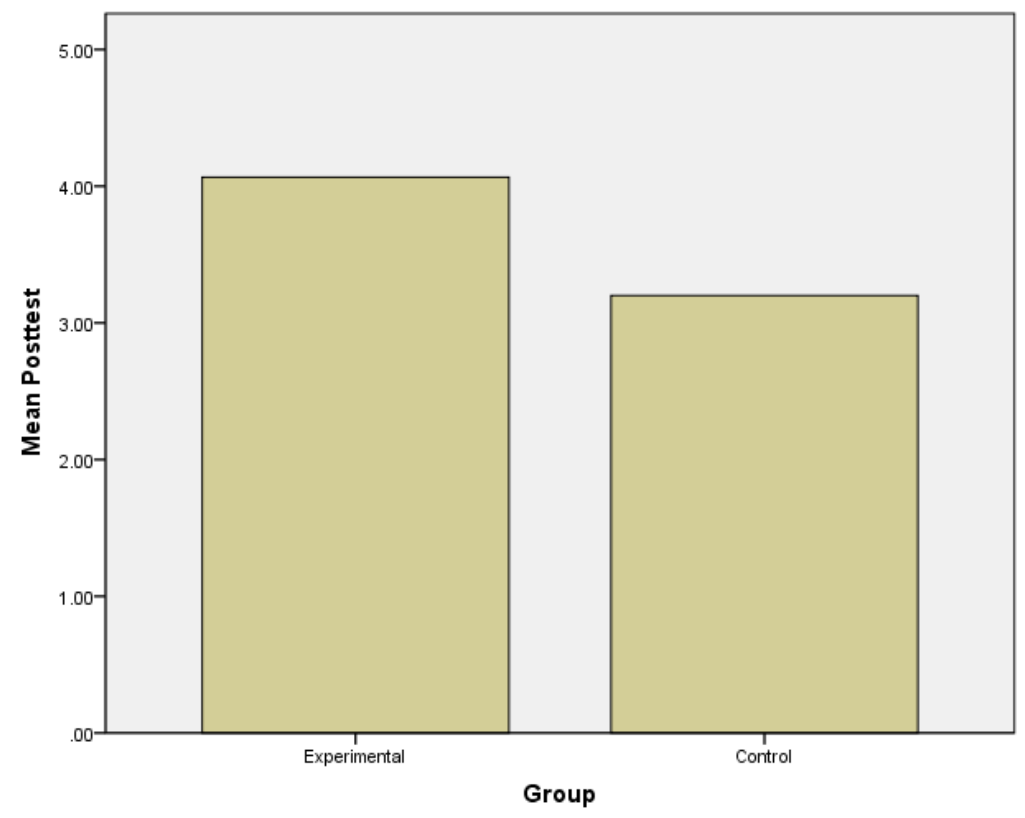

Figure 2. Mean scores for post-test

\subsection{Relationship between Gambits and Scores}

In fact, there is a relationship between the number of conversational gambits and the scores of speaking fluency test. Evidently, Table 5 shows descriptive statistics for the number of gambits and the post-test scores of fluency. Moreover, the results of the Chi-square test depict that there is a positive correlation between the number of gambits and the post- 


\section{International Journal of Research in English Education}

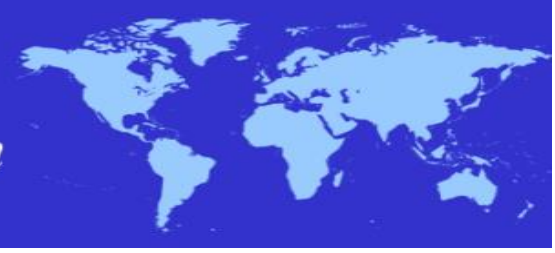

test scores of fluency test. As shown in Table 6, learners in the experimental group incorporate more gambits into their speaking and it leads to better speaking fluency. The correlation coefficient is .899 which means that the relationship is about $89 \%$ in this study.

Table 5. Descriptive Statistics for the number of gambits and the post-test scores of fluency test

\begin{tabular}{llll}
\hline & Mean & Std. Deviation & N \\
\hline Fluency post-test scores & 4.0667 & .82768 & 30 \\
Number of gambits & 22.6000 & 6.38749 & 30 \\
\hline
\end{tabular}

Table 6. Chi-square test for the number of gambits and the post-test scores of fluency test

\begin{tabular}{llll}
\hline & & $\begin{array}{c}\text { Fluency post-test } \\
\text { scores }\end{array}$ & Number of gambits \\
\hline \multirow{3}{*}{ Fluency post-test scores } & Pearson Correlation & 1 & $.899^{* *}$ \\
& Sig. (2-tailed) & & .000 \\
& $\mathrm{~N}$ & 30 & 30 \\
Number of gambits & Pearson Correlation & $.899^{* *}$ & 1 \\
& Sig. (2-tailed) & .000 & \\
& $\mathrm{~N}$ & 30 & 30 \\
\hline
\end{tabular}

**. Correlation is significant at the 0.01 level (2-tailed).

\section{Discussion}

The present study investigated the contributory role of conversational gambits and routines in improving speaking fluency of Iranian intermediate EFL learners. In other words, this research study proved that using conversational fillers and formulas not only help students speak more fluently but also lead to better confidence. Furthermore, the number of gambits that learners produce in their interactions inevitably influences the scores they accomplish in speaking fluency tests. In line with Yorio (1992), this study revealed that conversational gambits and routines can improve speaking fluency of Iranian intermediate EFL learners.

The results of the t-test revealed that the experimental group possessed better speaking fluency based on the occurrences of gambit categories. In agreement with Kelller (1981), there was a positive correlation between the number of gambits and the scores of fluency test. In line with this, the more gambits and routines learners use while communicating, the better scores they achieve in the speaking fluency tests. To conclude, utilization of conversational gambits and routines improves the speaking fluency of Iranian intermediate EFL learners.

The findings of the present investigation are, furthermore, in line with the results of the study conducted by Sorhus (1997) in that many utterances and sentences used in daily interactions and communications are in one way or another fixed expressions and features. The integration of conversational gambits and routines in speaking can facilitate speaking fluency and maintain a smooth flow of conversation. In this regard, the incorporation of conversational gambits, fixed expressions, and formulaic patterns into spoken form of language can help interlocutors comprehend sentences more easily. Moreover, similar to Coulmas' research study (1981), conversational gambits and routine formulas can help avoid breakdowns in communication by and large.

\section{Implications of This Study}

Evidently, the findings of the present study may have implications for EFL teachers and syllabus designers. To clarify, material developers and EFL teachers can facilitate speaking fluency of students by motivating them to make use of conversational gambits and routines not only in institutional settings but also in outside circumstances. In addition, the results of this research study may provide significant help for students who are learning English as a foreign 


\section{International Journal of Research in English Education}

language and seeking ways to improve their speaking fluency through social interactions. Furthermore, learners become acquainted with conversational gambits and formulas; consequently, they fill in the gaps they might have in their speaking and interaction. Finally, they improve their confidence and motivation when they learn how to fill the pauses and hesitations in speaking.

\section{Conclusion}

The current research study attempted to examine the beneficial effect of conversational gambits and routines on speaking fluency of Iranian intermediate EFL learners. Accordingly, this investigation proved that utilization of conversational gambits and formulaic routines can facilitate and improve the speaking fluency of Iranian intermediate EFL learners. Moreover, there was a positive correlation between the number of gambits and the scores of fluency test. To conclude, conversational gambits and routines can help learners to speak more fluently and confidently not only in class but also in social communications and interactions. In addition, the utilization of gambits and formulas in speech can avoid breakdowns in communication and conversation. Another concluding remark is that the more conversational gambits and routines are used in speech, the higher scores can be achieved in the speaking test. This study can be carried out in other educational settings such as high schools and junior high schools. Moreover, the present study might be replicated in other cities with different English language exposures, language backgrounds, and proficiency levels. Additionally, the impact of gambits and routines on speaking accuracy and intonation of Iranian EFL learners can be investigated.

\section{References}

Coulmas, F. (1981). Conversational routine: Explorations in standardized communication situations and prepatterned speech. The Hague: Moutan. https://doi.org/10.1017/S0047404500000208

Edwards, L. (2007). Oxford solutions placement test. Oxford: Oxford University Press.

Faerch, C., \& Kasper, G. (1983). Plans and strategies in foreign language communication. In C. Faerch \& G. Kasper (Eds.), Strategies in interlanguage communication (pp. 20-60). New York: Longman.

Keller, E. (1979). Gambits: Conversational strategy signals. Journal of Pragmatics, 3(3/4), 219-238.

Keller, E. (1981). Gambits: Conversational strategy signals. In F. Coulmas (Ed.), Conversational routine (pp. 93-113). The Hague, Netherlands: Mouton.

Keller, E., \& Warner, S. T. (1994). Gambits. England: Canadian Government Publication Centre. Longman dictionary of American English ( $4^{\text {th }}$ Ed.). England: Laurence Delacroix.

Keller, E., \& Warner, S. T. (2002). Conversation gambits: Real English conversation practices ( $3^{\text {rd }}$ Ed.). Boston: Language Teaching Publications.

Kormos, J., \& Dénes, M. (2004). Exploring measures and perceptions of fluency in the speech of second language learners. System, 32(2), 145-164.

Norton, D. E. (1980). The effective teaching of language arts. Columbus, Ohio: C.E. Merrill Pub. Co., c1980. https://trove.nla.gov.au/version/30098707

Roever, C. (2011). What learners get for free: Learning of routine formulae in ESL and EFL environments. ELT Journal, 66(1), 10-21. doi: 10.1093/elt/ccq090

Sorhus, H. B. (1997). To hear ourselves: Implications for the teaching of English as a second language. English Language Teaching Journal, 31(3), 211-221. https://eric.ed.gov/?id=EJ158998

Weinert, R. (1995). The role of formulaic language in second language acquisition: A review. Applied Linguistics, 16(2), 180-205. doi: 10.1093/applin/16.2.180

Wray, A. (2000). Formulaic sequences in second language teaching: Principle and practice. Applied Linguistics, 21(4), 463-489. https://doi.org/10.1093/applin/21.4.463

Yorio, C. A. (1980). Conventionalized language forms and the development of communicative competence. TESOL Quarterly, 14(4), 433-442. https://eric.ed.gov/?id=EJ236859 


\section{International Journal of Research in English Education}

Yorio, C. A. (1992). Idiomaticity as an indicator of second language proficiency. In K. Hyltenstam \& L. K. Obler (Eds.), Bilingualism across the lifespan: Aspects of acquisition, maturity, and loss (pp. 55-72). Cambridge, England: Cambridge University Press. 